\title{
STATIC ANALYSIS OF HELICAL COMPRESSION SPRING
}

\author{
Sangmesh Pattar ${ }^{1}$, Sanjay S.J ${ }^{2}$, V.B.Math ${ }^{3}$ \\ ${ }^{I}$ P.G. Student, Mechanical Engineering Department, Basaveshwar Engineering College, Karnataka, India \\ ${ }^{2}$ Assistant Professor, Mechanical Engineering Department, Basaveshwar Engineering College, Karnataka, India \\ ${ }^{3}$ Professor, Mechanical Engineering Department, Basaveshwar Engineering College, Karnataka, India
}

\begin{abstract}
A spring is a flexible element used to exert a force or a torque and, at the same time, to store the energy. The force can be a linear push or pull, or it can be radial, acting similarly to a rubber band around a roll of drawings. The spring which is considered in the paper is a part of automobile horn, where the horn is used for maintain safe distance and it is subjected to varying load. The spring is analyzed through analytical and finite element method to check the variation in the deformation value as well as maximum shear stress value. By the results of ANSYS it is observed that analytical results and finite element method results are within the acceptable range.
\end{abstract}

Keywords: Spring, Automobile Horn, Finite Element Method.

\section{INTRODUCTION}

A spring is defined as an elastic body, whose function is to compress when loaded and to recover its original shape when the load is removed. A spring is a flexible element used to exert a force or a torque and, at the same time, to store energy. The force can be a linear push or pull, or it can be radial. The torque can be used to cause a rotation. Springs can be classified according to the direction and the nature of the force exerted by the spring when it is deflected. Helical compression springs are typically made from round wire, wrapped into a straight, cylindrical form with a constant pitch between adjacent coils. Square or rectangular wire may also be used. Without an applied load, the spring's length is called the free length. When a compression force is applied, the coils are pressed more closely together until they all touch, at which time the length the minimum possible is called the solid length.

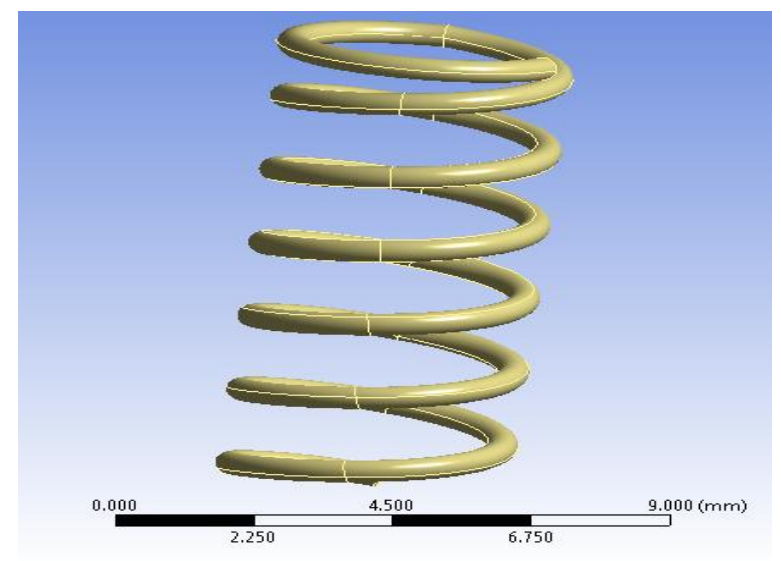

Fig -1: Model of spring
A static analysis is carried on helical compression spring which is used in two-wheeler horn by S.S.Gaikwad et.al[1],in his paper analytical results are compared with NASTRON software results. Varun B. and K. K. JAIN [2], they considered helical spring which is subjected heavy duty or load.

\author{
Notations \\ D - Mean Diameter of Coil. \\ d - Diameter of Wire. \\ 1 - Total Length of Wire. \\ $\mathrm{n}$ - No. of active Coils. \\ $\tau$ - Maximum Shear Stress. \\ $\theta$ _ Angular deflection of the Wire. \\ $\mathrm{T}$ - Twisting Moment. \\ J - Polar Moment of Inertia. \\ W - Load. \\ C - Spring Index. \\ $\Delta$ - Deflection of the Spring. \\ $\mathrm{G}$ - Modulus of Rigidity for the spring material.
}

\section{ANALYTICAL METHOD}

In design of helical spring, initially spring considered as per some dimensions like free length of spring, wire diameter, mean diameter of spring, pitch of spring this dimensions either as per calculation or as per application. But when it is subjected to load then spring will act according to load and get deformed or stressed so, it is important to know when spring is subjected to load what is the maximum deflection and maximum shear stress. Some other values are also considered but in this paper only deflection and maximum shear stress are considered because of application of spring needs these 
values. To calculate deflection and maximum shear stress formulas are below.

Deflection of Helical Spring of circular wire can be calculated by [3],

$$
\begin{aligned}
& \delta=\theta x D / 2 \\
& \frac{T}{J}=\frac{\tau}{d / 2}=\frac{G \theta}{l}
\end{aligned}
$$

Therefore $\theta=\frac{T l}{J G}$ or $\theta=\frac{\tau l}{G D / 2} \quad \theta=\frac{T l}{J G}$ and substituting value of $\theta$ in Eq. 1

We get $\delta=\frac{8 W D^{3} n}{G d^{4}}=\frac{8 W C^{3} n}{G d}$

$$
\mathrm{C}=\mathrm{D} / \mathrm{d}
$$

Stress in Helical Spring of circular wire can be calculated by,

$T=W x D / 2=\frac{\pi}{16} \tau_{1} d^{3}$

$\tau_{1}=\frac{8 W D}{\pi d^{3}}$ and $\tau_{2}=\frac{4 W}{\pi d^{2}}$

The Resultant Shear Stress is given by

$$
\tau=\tau_{1}+\tau_{2}=\frac{8 W D}{\pi d^{3}}+\frac{4 W}{\pi d^{2}}
$$

\section{FINETE ELEMENT METHOD}

The finite element method is a numerical method for solving problems of engineering and mathematical physics. Typical problem areas of interest in engineering and mathematical physics that are solvable by use of the finite element method include structural analysis, heat transfer, fluid flow, mass transport and electromagnetic potential. For problems involving complicated geometries, loading and material properties, it is generally not possible to obtain analytical mathematical solutions. Analytical solutions are those given by a mathematical expression that yields the values of the values of the desired unknown quantities at any location in a body and are thus valid for a finite number of locations in the body. These analytical solutions generally require the solution of ordinary or partial differential equations, which because of the complicated geometries, loading and material properties are not usually obtainable[4].

\section{LOADING AND BOUNDARY CONDITION}

Component is modeled in CAD software [ ]. Spring consists of following dimensions, wire diameter $=0.45 \mathrm{~mm}$, Pitch $=$ $1.75 \mathrm{~mm}$, mean diameter of spring $=4.35 \mathrm{~mm}$, free length of spring $=10.2 \mathrm{~mm}$, no. of active coil $=6$. For analysis ANSYS 14.5 (workbench) is used. Since spring used in horn so, load applied is small and in this case it is considered as $1 \mathrm{~N}$. Load is varied as $1 \mathrm{~N}, 2 \mathrm{~N}, 3 \mathrm{~N}, 4 \mathrm{~N}, 5 \mathrm{~N}$. The spring material properties are as mention in below table.

Table -1: Material Properties of spring

\begin{tabular}{|l|l|}
\hline Material & Stainless Steel \\
\hline Modulus of elasticity & $193000 \mathrm{~N} / \mathrm{mm}^{2}$ \\
\hline Poisson's ration & 0.3 \\
\hline Density & $8 \mathrm{E}-09$ tones $/ \mathrm{mm}^{3}$ \\
\hline Shear modulus & $588.99 \mathrm{~N} / \mathrm{mm}^{2}$ \\
\hline
\end{tabular}

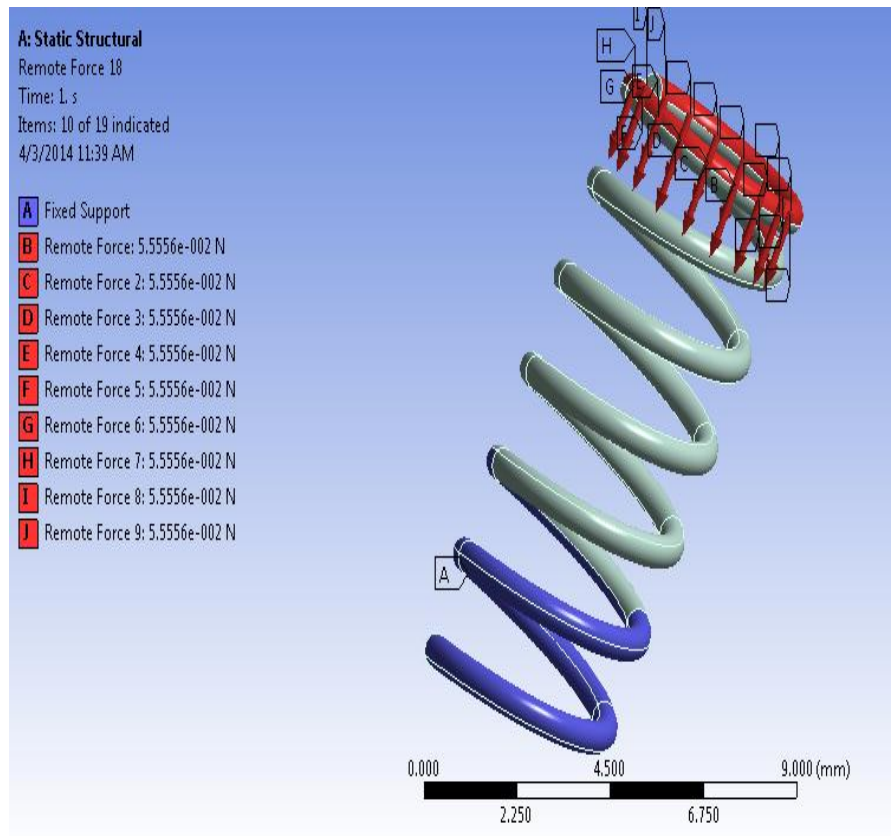

Fig -2: Fixed support and load distribution.

In ANSYS software first the material properties are added, and then CAD model is imported. In analysis part model is meshed with required size, element (Tetra or Quadra) then with boundary conditions. The component is loaded, in this case spring fixed (all degrees of freedom are constrained) at one end and other end is loaded. At last checking the required results in this case deformation and maximum shear stress. 


\section{RESULTS AND DISCUSSION}

Below table values are obtained by theoretical and ANSYS

Table -2: Theoretical values for load distribution

\begin{tabular}{|l|l|l|}
\hline $\begin{array}{l}\text { Load } \\
\text { in } \mathrm{N}\end{array}$ & $\begin{array}{l}\text { Deformation } \\
\text { in } \mathrm{mm}\end{array}$ & $\begin{array}{l}\text { Maximum shear } \\
\text { stress in } \mathrm{N} / \mathrm{mm}^{2}\end{array}$ \\
\hline 1 & 0.9176 & 127.83 \\
\hline 2 & 1.835 & 255.66 \\
\hline 3 & 2.7529 & 383.49 \\
\hline 4 & 3.6705 & 511.38 \\
\hline 5 & 4.5881 & 639.16 \\
\hline
\end{tabular}

Table-3: ANSYS values for load distribution

\begin{tabular}{|l|l|l|}
\hline $\begin{array}{l}\text { Load } \\
\text { in N }\end{array}$ & $\begin{array}{l}\text { Deformation in } \\
\mathrm{mm}\end{array}$ & $\begin{array}{l}\text { Maximum shear stress } \\
\text { in N/mm2 }\end{array}$ \\
\hline 1 & 0.3995 & 151.33 \\
\hline 2 & 0.9019 & 204.97 \\
\hline 3 & 1.3529 & 307.45 \\
\hline 4 & 1.9958 & 409.83 \\
\hline 5 & 2.5459 & 515.47 \\
\hline
\end{tabular}

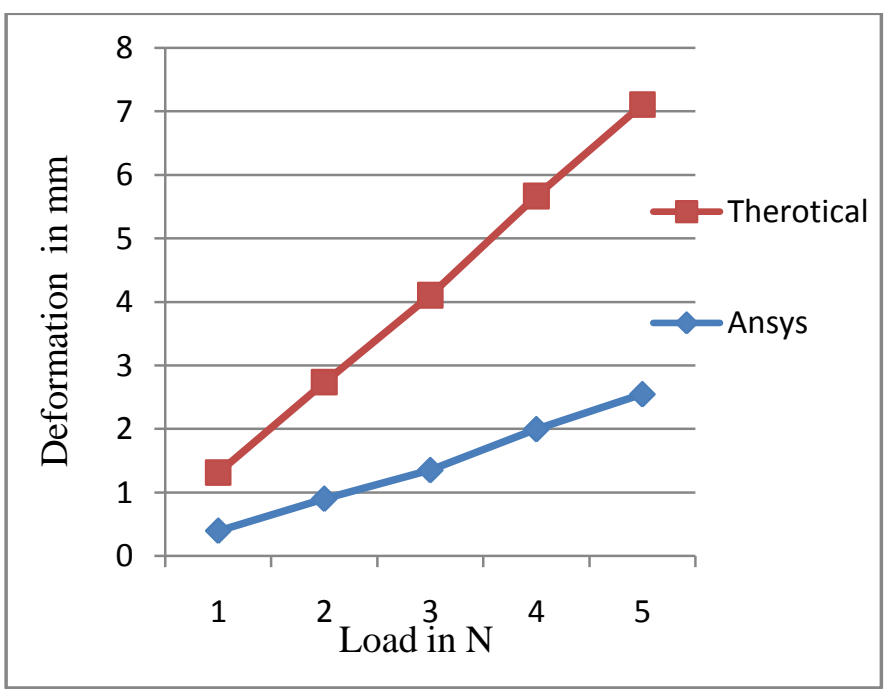

Fig -3: Load vs Deformation.

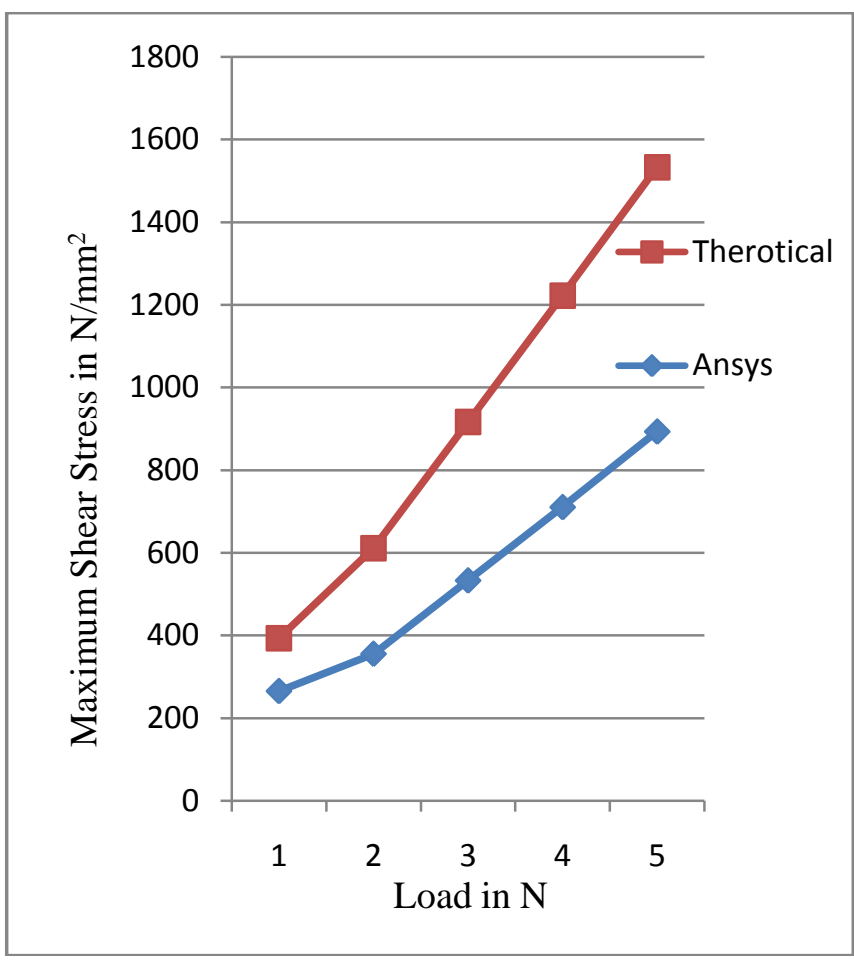

Fig -4: Load vs Maximum shear stress.

\section{CONCLUSIONS}

The spring which is used in the automobile horn is necessary to be analyzed in the context of maximum safe load of helical spring. In the present work helical compression spring is modeled and static analysis carried out by using ANSYS V14.5. it is observed that maximum stress is developed at the inner side of the coil. From the ANSYS and theoretical, the allowable design stress is found between the corresponding loads 2 to $5 \mathrm{~N}$. It is seen that at $7 \mathrm{~N}$ load, it crosses the yield stress (yield stress is $903 \mathrm{~N} / \mathrm{mm} 2$ ). By considering the factor of safety 1.5 to 2 . It is obvious that the allowable design stress is 419 to $838 \mathrm{~N} / \mathrm{mm} 2$. So the corresponding loads are 2 to $5 \mathrm{~N}$. Therefore it is concluded that the maximum safe pay load for the given specification of the helical compression spring is $4 \mathrm{~N}$. At lower loads both theoretical and ANSYS results are within the range, but when load increases the ANSYS results are uniformly reduced compared to theoretical results.

\section{ACKNOWLEDGEMENTS}

I take this opportunity to express my gratitude to my guide Prof.Sanjay.S.J and Dr.V.B.Math for their kind co-operation during this period. Their constant motivation enabled me to widen the horizon of my paper work and interest. 


\section{REFERENCES}

[1]. S. S. Gaikwad, P. S. Kachare (2013), "Static analysis of helical compression spring used in two-wheeler horn". IJEAT ISSN: 2249 - 8958, Volume-2, Issue-3.

[2]. Varun B, K. K. Jain (2013), "Analysis of closed coil helical spring subjected to heavy duty", IJEAT ISSN: 23200804 , Vol. 1 Issue -4.

[3]. R.S.Kurmi and J.K.Gupta (2005), Machine design, 3rd edition, S.Chand publication, India.

[4]. D. Logan (2005), Finite element method, 5th edtion, Celgage Learing, India.

[5]. ANSYS user manual 2014.

[6]. CATIA user manual V5R20. 